\title{
Optimization of Weibull deteriorating items inventory model under the effect of price and time dependent demand with partial backlogging
}

\author{
SHIV KUMAR ${ }^{1, *}$, ABHAY KUMAR SINGH ${ }^{1}$ and MANOJ KUMAR PATEL ${ }^{2}$ \\ ${ }^{1}$ Department of Applied Mathematics, Indian School of Mines, Dhanbad 826004, India \\ ${ }^{2}$ Department of Mathematics, National Institute of Technology, Dimapur, Nagaland 797103, India \\ e-mail: manshashiva@gmail.com; itbhu81@gmail.com; mkpitb@gmail.com
}

MS received 18 February 2016; revised 17 March 2016; accepted 1 April 2016

\begin{abstract}
In this study, we have discussed the development of an inventory model when the deterioration rate of the item follows Weibull two parameter distributions under the effect of selling price and time dependent demand, since, not only the selling price, but also the time is a crucial factor to enhance the demand in the market as well as affecting the overall finance. In the present model, shortages are approved and also partially backlogged. Optimum inventory level, the optimal length of a cycle and the expressions for profit function under various cost considerations are obtained using differential equations. These are illustrated graphically with the help of numerical examples. The sensitivity analysis of the standards of the parameters has been performed to study the effect on inventory optimizations.
\end{abstract}

Keywords. Inventory; deteriorating items; Weibull distribution; shortage; time and price dependent demand.

\section{Introduction}

The primary aim of any organization or industry is to attain maximum profit without losing items. An inventory system faces the problem of shortages due to deterioration of the items which create the loss of profit. The present market is full of competitive environment, hence it becomes necessary to model an inventory system policy to get more and more profit without losing the items as well as without sufficient increment in the selling price of the product. The control and protection of inventories of deteriorating goodwill have received much attention of many researchers even in current years.

In reality, the current demands are not satisfied due to damaged or decayed items. Deterioration or physical depletion or decay which is a physical process like (i) deterioration, as in perishable food stuff, fruits, and vegetables; (ii) physical depletion as in evaporation of volatile liquids such as perfumes, alcohol, and gasoline; and (iii) radioactive substances means decay substances, loss of potency as in photographic films, pharmaceutical drugs, and fertilizers, implies that the item is not in a state to use for its original purpose since when the deterioration starts, the utility of the product always decreases from the original condition.

*For correspondence
The shortage is defined as a fraction of those customers whose demand is not satisfied. When the shortage occurs, it is generally assumed that the demand is either backlogged or lost. But practically it is observed that few customers are always willing to wait for backorder while other customers are turning to buy from different retailers, this situation is termed as partial backlogging. It is also noticed that the demand rate is usually influenced by the selling price of the product. Therefore, it is very important to model the demand pattern and deteriorating behavior of such type of inventory. The items in which the deterioration rate follows the Weibull distribution are pasteurized milk, corn seed, roasted ground coffee, frozen foods, refrigerated meats and ice creams. While discussing the fitting of the empirical data to mathematical distribution, it is noticed that the life expectancy of ethical drugs and the leakage failure of dry batteries could be expressed in the case of the Weibull distribution in [1]. In both the cases, the deterioration rate is greater than before with time/age or in other word the longer the items are remaining unused, the failure rate will be high. In [2], they have reconsidered the work of [3] to develop a model where the demand rate is decreasing function of the selling price while the backlogging rate is time-dependent function. The general case of inventory model with ramp type demand and Weibull deterioration is studied in [4]. In [5], authors have developed an inventory model of Weibull distribution type rate of deterioration with price sensitive demand and studied the optimal dynamic price and maximum profit. The 
inventory models with ramp type demand rate, partial backlogging and Weibull deterioration rate have been derived in [6]. In [7], they have presented a model with time dependent two parameter, Weibull demand rate and variable deteriorating rate which is increasing with time. The effects of inflation on an EOQ model with stock-dependent demand, and time-dependent partial backlogging of deteriorating items under time discounting is discussed in [8]. In [9], authors have explained an analytical solution of an inventory model of Weibull deteriorating items with time dependent power pattern demand. An inventory model of three parameter Weibull deteriorating item, constant demand with partial backlogging and derived optimal is profitable plan for business organization which is needed since there is a lot of competition throughout these days studied in [10]. In [11], they have also developed an EOQ model of two parameter, Weibull deteriorating good-will with partial backlogging but considering power demand. An economic order quantity model for Weibull deteriorating items with stock dependent consumption rate and shortages under inflation have been considered in [12]. In [13], authors have derived an inventory model of deteriorating items with time dependent demand, constant holding cost and shortages in the case of partially backlogged. An improved EOQ model for items with Weibull distribution deterioration is discussed in [14]. In [15], they have worked on economic production lot size model with deteriorating items, stock-dependent demand, inflation, and partial backlogging. An EOQ inventory model for items with Weibull distribution deterioration, ramp type demand rate and partial backlogging has been examined in [16]. In [17] they have derived particle swarm optimization of a neural network model in a machining process. In [18], authors have explained multiple-vendor, multiple-retailer based vendor-managed inventory. Optimal replenishment policies for non-instantaneous deteriorating items with stockdependent demand have been examined in [19]. In [20], they have done operational research models applied to the fresh fruit supply chain. In [21], author has presented a waiting time deterministic inventory model for perishable items in stock and time dependent demand.

Based on the above studies, to fit realistic circumstances, an attempt has been made to develop an inventory model of two parameter Weibull type deteriorating items with the rate of demand as a function of two factors where the first factor is of decreasing nature with increasing selling price and the second factor is of exponentially decreasing nature with increasing time. Moreover shortage is allowed by considering the rate of backlogging as inversely proportional to waiting time of the next replenishment. The proposed model has been framed and studied with the objective which maximizes the profit of the system. The analysis is carried out to determine the optimal order quantity along with the optimal selling price with the help of numerical examples. With the help of mathematical software and using the Newton Raphson method the system of nonlinear equations are solved. The variation of profit with time and/or selling price is also shown graphically in figure. The sensitivity analysis, to study the effect on profit due to the changes of the values of the parameters associated with the model, has been performed.

\section{Proposed model}

The variation of inventory level of a cycle is depicted in figure 1. Initially at time $t=0, I_{0}$ amount of items is arrived, which is the initial on hand level of the inventory at the start of the cycle. During the time interval $\left[0, t_{1}\right]$ inventory level is depleted to zero due to demand as well as deterioration. The shortage is allowed to occur during the time interval $\left[t_{1}, T\right]$. The demand in the shortage period during stock out is partially backlogged or lost. The backlogging rate is a variable function of time, which depends on the waiting time for the next replenishment. The whole process is repeated.

\subsection{Notations}

The following fundamental notations are used to derive the model.

$\begin{array}{ll}A & \text { ordering cost per cycle } \\ c_{h} & \text { holding cost per unit per unit time } \\ c_{d} & \text { deteriorated cost per unit item } \\ c_{s} & \text { shortage cost per unit item } \\ c_{l} & \text { lost sale cost per unit item } \\ p & \text { purchase cost per unit item } \\ t_{1} & \text { time when inventory level reaches zero } \\ T & \text { duration of a cycle } \\ C F\left(t_{1}, T, p\right) & \text { cost function of the system } \\ I_{0} & \text { maximum inventory level } \\ I_{1}(t) & \text { inventory level at any time } t, 0<t<t_{1} \\ I_{2}(t) & \text { inventory level at any time } t, t_{1} \leq t \leq T \\ S & \text { shortage level } \\ Q & \text { ordering quantity } \\ \mu(t) & \text { deterioration rate of on hand inventory at any } \\ p & \text { time } t \\ D(t, p) & \text { selling price per unit of the item } \\ & \text { demand function }\end{array}$

\subsection{Assumptions}

The manufacturing organization is used to develop the following model:

(i) The rate of deterioration, $\mu(t)=\alpha \beta t^{\beta-1}$, considering a two parameter Weibull distribution where $\alpha(0<\alpha \leq 1)$ is the scale parameter, $\beta(\beta>0)$ is the shape parameter and $t(t>0)$ is deterioration time of the items. 


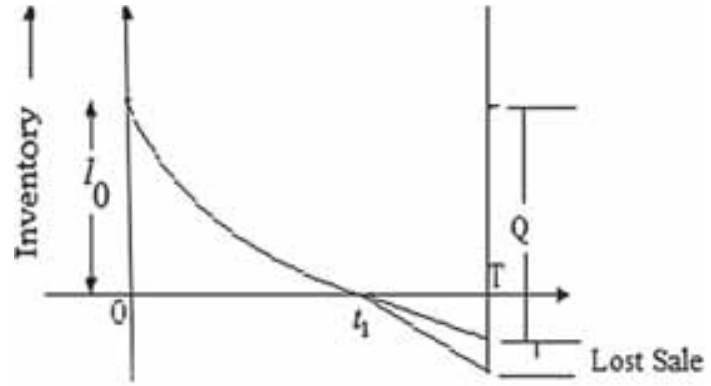

Time

Figure 1. Geometrical representation of inventory system.

(ii) $D(t, p)=\frac{e^{-\theta t}}{p}$, is the demand function where it is

decreasing exponentially with increasing time and it is inversely with the selling price $p$ and $\theta$ is a constant leading the decreasing rate of demand.

(iii) Lead time is zero

(iv) Replenishment is instantaneous.

(v) The shortage period is also occurring in the rate of backlogging, depends on the length of waiting time and is defined as $B(t)=\frac{1}{1+\delta(T-t)}$ where only a fraction $\delta(0 \leq 1 \leq 1)$ of the shortage is backlogged and the remaining fraction $(1-\delta)$ is lost. $(T-t)$ is the waiting time for the next replenishment and $\delta$ denotes the backlogging parameter.

\subsection{Mathematical analysis}

The inventory system is basically as leads $I_{0}$ units of items are the on hand inventory at the beginning of a cycle. The level of the inventory drops to zero due to demand and also Weibull pattern deterioration or in other word the variation of inventory level changes with respect to time $t$ and the effects of demand as well as Weibull deterioration. If $I_{1}(t)$ be the on hand inventory at any time $t \geq 0$, then at time $t+\Delta t$, in the interval $[0, t]$ the inventory is expressed as

$$
I_{1}(t+\Delta t)=I_{1}(t)-\mu(t) I_{1}(t) \Delta t-D(t, p) \Delta t
$$

where the deteriorating rate $\mu(t)=\alpha \beta t^{\beta-1}$ and the demand function $D(t, p)=\frac{e^{-\theta t}}{p}$.

First, dividing both sides by $\Delta t$ and then taking the limit as $\Delta t \rightarrow 0$ gives

$$
\frac{d I_{1}(t)}{d t}+\mu(t) I_{1}(t)=-D(t, p) ; \quad 0 \leq t \leq t_{1} .
$$

With initial condition are

$$
I_{1}(t)=I_{0} \text { at } t=0 \quad \text { and } \quad I_{1}(t)=0 \quad t=t_{1} .
$$

Solving the above differential equation (2.1) along with the initial boundary conditions, the inventory level $I_{1}(t)$ at any time $t$ is described as follows:

$$
\begin{aligned}
I_{1}(t)= & \frac{1}{p}\left[t+\frac{\alpha t^{1+\beta}}{(1+\beta)}+\frac{\alpha^{2} t^{1+2 \beta}}{2(1+\beta)}-\frac{\theta t^{2}}{2}-\frac{\alpha \theta t^{2+\beta}}{(2+\beta)}\right. \\
& \left.-\frac{\alpha^{2} \theta t^{2(1+\beta)}}{4(1+\beta)}+\frac{\theta^{2} t^{3}}{3}\right] e^{-\alpha t^{\beta}}+I_{0} e^{-\alpha t^{\beta}}
\end{aligned}
$$

Using boundary condition, Eq. (2.2) gives the initially on hand inventory level $I_{0}$ as

$$
\begin{aligned}
I_{0}= & \frac{1}{p}\left[t_{1}+\frac{\alpha t_{1}^{1+\beta}}{(1+\beta)}+\frac{\alpha^{2} t_{1}^{1+\beta}}{2(1+\beta)}-\frac{\theta t_{1}^{2}}{2}-\frac{\alpha \theta t_{1}^{2+\beta}}{(2+\beta)}\right. \\
& \left.-\frac{\alpha^{2} \theta t_{1}^{2+\beta}}{4(1+\beta)}+\frac{\theta^{2} t_{1}^{3}}{3}\right] .
\end{aligned}
$$

Using the above calculated initially on hand inventory level $I_{0}$, Eq. (2.2) reduces to

$$
\begin{aligned}
I_{1}(t)= & \frac{1}{p}\left[t+\frac{\alpha t^{1+\beta}}{(1+\beta)}+\frac{\alpha^{2} t^{1+2 \beta}}{2(1+\beta)}-\frac{\theta t^{2}}{2}-\frac{\alpha \theta t^{2+\beta}}{(2+\beta)}\right. \\
& \left.-\frac{\alpha^{2} \theta t^{2(1+\beta)}}{4(1+\beta)}+\frac{\theta^{2} t^{3}}{3}\right] e^{-\alpha t^{\beta}} \\
& +\left[t_{1}+\frac{\alpha t_{1}^{1+\beta}}{(1+\beta)}+\frac{\alpha^{2} t_{1}^{1+\beta}}{2(1+\beta)}-\frac{\theta t_{1}^{2}}{2}-\frac{\alpha \theta t_{1}^{2+\beta}}{(2+\beta)}\right. \\
& \left.-\frac{\alpha^{2} \theta t_{1}^{2+\beta}}{4(1+\beta)}+\frac{\theta^{2} t_{1}^{3}}{3}\right] .
\end{aligned}
$$

The demand in shortage period at the time interval $\left[t_{1}, T\right]$ during stock out is partially backlogged or in other word the variation of the shortage level $I_{2}(t)$ at any time $t$ during the interval $\left[t_{1}, T\right]$ is fulfilled by partial-backlogging. The backlogging rate is $B(t)=\frac{1}{1+\delta(T-t)}$ where $\delta$ is the backlogging parameter and $(T-t)$ is the waiting time for the next replenishment. The whole process is repeated.

During the time interval $\left[t_{1}, T\right]$ the inventory level depends on demand and a fraction of the demand is backlogged. If $I_{2}(t)$ be the replenishment at the time $t\left(t \geq t_{1}\right)$, then at the time $t+\Delta t$ in the time interval $\left[t_{1}, \mathrm{~T}\right]$, the replenishment will be

$$
I_{2}(t+\Delta t)=I_{2}(t)-\frac{D(t, p)}{1+\delta(T-t)} \Delta t .
$$

Dividing first both side by $\Delta t$ and then taking limit as $\Delta t \rightarrow 0$ gives

$$
\frac{d I_{2}(t)}{d t}=-\frac{D(t, p)}{1+\delta(T-t)}, \quad t_{1} \leq t \leq T .
$$

The boundary condition are

$$
I_{2}(t)=0 \text { at } t=t_{1} \text { and } I_{2}(t)=-S \text { at } t=T .
$$


The solution of Eq. (2.5) is represented by

$$
\begin{aligned}
I_{2}(t)= & \frac{1}{p}\left[\left(\frac{1-\delta T}{\theta^{2}}\right) \delta^{2} T^{2}\left(e^{-\theta t}-e^{-\theta t_{1}}\right)\right. \\
& -2\left(\frac{1-\delta T}{\theta^{2}}\right) \delta\left\{e^{-\theta t}(\theta t+1)-e^{-\theta t_{1}}\left(\theta t_{1}+1\right)\right\} \\
& \left.+\frac{\delta^{2}}{\theta^{3}}\left\{e^{-\theta t}\left(\theta t^{2}+2 \theta t+2\right)-e^{-\theta t_{1}}\left(\theta t_{1}^{2}+2 \theta t_{1}+2\right)\right\}\right] .
\end{aligned}
$$

The replenishment demanded backlogged level in the time interval $\left[t_{1} T\right]$ of a cycle is given below, using Eq. (2.6), with the boundary condition

$$
\begin{aligned}
S \equiv & -I_{2}(T)=-\frac{1}{p}\left[\left(\frac{1-\delta T}{\theta^{2}}\right) \delta^{2} T^{2}\left(e^{-\theta T}-e^{-\theta t_{1}}\right)\right. \\
& -2\left(\frac{1-\delta T}{\theta^{2}}\right) \delta\left\{e^{-\theta T}(\theta T+1)-e^{-\theta t_{1}}\left(\theta t_{1}+1\right)\right\} \\
& \left.+\frac{\delta^{2}}{\theta^{3}}\left\{e^{-\theta T}\left(\theta T^{2}+2 \theta T+2\right)-e^{-\theta t_{1}}\left(\theta t_{1}^{2}+2 \theta t_{1}+2\right)\right\}\right] .
\end{aligned}
$$

The next order quantity $Q$, which is the sum of the on hand inventory $I_{0}$ together with the replenishment demanded backlogged $S$, is represented by

$$
\begin{aligned}
Q= & I_{0}+S \text { or } \\
Q= & \frac{1}{p}\left[t_{1}+\frac{\alpha t_{1}^{1+\beta}}{(1+\beta)}+\frac{\alpha^{2} t_{1}^{1+\beta}}{2(1+\beta)}-\frac{\theta t_{1}^{2}}{2}-\frac{\alpha \theta t_{1}^{2+\beta}}{(2+\beta)}\right. \\
& \left.-\frac{\alpha^{2} \theta t_{1}^{2+\beta}}{4(1+\beta)}+\frac{\theta^{2} t_{1}^{3}}{3}\right]+\frac{1}{p}\left[\left(\frac{1-\delta T}{\theta^{2}}\right) \delta^{2} T^{2}\left(e^{-\theta T}-e^{-\theta t_{1}}\right)\right. \\
& -2\left(\frac{1-\delta T}{\theta^{2}}\right) \delta\left\{e^{-\theta T}(\theta T+1)-e^{-\theta t_{1}}\left(\theta t_{1}+1\right)\right\} \\
& \left.+\frac{\delta^{2}}{\theta^{3}}\left\{e^{-\theta T}\left(\theta T^{2}+2 \theta T+2\right)-e^{-\theta t_{1}}\left(\theta t_{1}^{2}+2 \theta t_{1}+2\right)\right\}\right] .
\end{aligned}
$$

Total sales revenue per unit per cycle is calculated as

$$
\begin{aligned}
S R= & p\left[\int_{0}^{t_{1}} D(t, p) d t-I_{2}(T)\right] \text { or } \\
S R= & {\left[\frac{1}{\theta}\left(e^{-\theta t_{1}}-1\right)+\left[\left(\frac{1-\delta T}{\theta^{2}}\right) \delta^{2} T^{2}\left(e^{-\theta T}-e^{-\theta t_{1}}\right)\right.\right.} \\
& -2\left(\frac{1-\delta T}{\theta^{2}}\right) \delta\left\{e^{-\theta T}(\theta T+1)-e^{-\theta t_{1}}\left(\theta t_{1}+1\right)\right\} \\
& \left.+\frac{\delta^{2}}{\theta^{3}}\left\{e^{-\theta T}\left(\theta T^{2}+2 \theta T+2\right)-e^{-\theta t_{1}}\left(\theta t_{1}^{2}+2 \theta t_{1}+2\right)\right\}\right] .
\end{aligned}
$$

Using the following relevant inventory cost factor per unit per cycle, the cost function has been calculated

(a) A is the setup cost per cycle.

(b) Inventory holding/storage cost of the system is given by

$$
\begin{gathered}
H C=c_{h}\left[\int_{0}^{t_{1}} I_{1}(t) d t\right] \\
H C=\frac{C_{h}}{p}\left[\frac{t_{1}^{2}\left(\theta^{2} t_{1}^{2}+6\right)}{12}+\frac{\alpha \beta t_{1}^{2+\beta}}{(1+\beta)(2+\beta)}\right. \\
-\frac{\left(1+3 \beta+4 \beta^{2}\right) \alpha^{2} t_{1}^{2(1+\beta)}}{4(1+\beta)^{2}(1+2 \beta)}-\frac{\alpha^{2} \beta^{2} t_{1}^{3+2 \beta}}{(1+\beta)(1+2 \beta)(3+2 \beta)} \\
-\frac{\alpha^{4} \theta t_{1}^{3+4 \beta}}{4(1+2 \beta)(3+4 \beta)}-\frac{\alpha \theta^{2} t_{1}^{4+\beta}}{(1+\beta)(4+\beta)}-\frac{\alpha \beta \theta t_{1}^{3+\beta}}{2(2+\beta)(3+\beta)} \\
-\frac{\alpha^{2} \theta^{2} t_{1}^{2(2+\beta)}}{12(2+\beta)}-\frac{\alpha^{2} t_{1}^{(1+\beta)^{2}}}{(1+\beta)^{2}}+\frac{\alpha^{4} t_{1}^{2(1+\beta)}}{4(1+\beta)^{2}} \\
\left.-\frac{\alpha \beta \theta t_{1}^{3+\beta}}{2(1+\beta)(2+\beta)}+\frac{\alpha^{3} \beta \theta t_{1}^{3(1+\beta)}}{4(2+\beta)(1+2 \beta)}+\frac{\alpha^{2} \theta^{2} t_{1}^{3(2+\beta)}}{6(1+2 \beta)}\right] .
\end{gathered}
$$

(c) The deterioration cost per cycle is represented by

$$
\begin{aligned}
D C= & c_{d}\left[I_{0}-\int_{0}^{t_{1}} D(t, p) d t\right] \\
= & \frac{c_{d}}{p}\left[\left\{t_{1}+\frac{\alpha t_{1}^{1+\beta}}{(1+\beta)}+\frac{\alpha^{2} t_{1}^{1+\beta}}{2(1+\beta)}-\frac{\theta t_{1}^{2}}{2}-\frac{\alpha \theta t_{1}^{2+\beta}}{(2+\beta)}\right.\right. \\
& \left.\left.-\frac{\alpha^{2} \theta t_{1}^{2+\beta}}{4(1+\beta)}+\frac{\theta^{2} t_{1}^{3}}{3}\right\}+\frac{1}{\theta}\left(e^{-\theta t_{1}}-1\right)\right] .
\end{aligned}
$$

(d) The purchase cost for order quantity is expressed as the total $P C=c Q$

$$
\begin{aligned}
\Rightarrow & P C=\frac{c}{p}\left[t_{1}+\frac{\alpha t_{1}^{1+\beta}}{(1+\beta)}+\frac{\alpha^{2} t_{1}^{1+\beta}}{2(1+\beta)}-\frac{\theta t_{1}^{2}}{2}-\frac{\alpha \theta t_{1}^{2+\beta}}{(2+\beta)}\right. \\
& \left.-\frac{\alpha^{2} \theta t_{1}^{2+\beta}}{4(1+\beta)}+\frac{\theta^{2} t_{1}^{3}}{3}\right]+\frac{c}{p}\left[\left(\frac{1-\delta T}{\theta^{2}}\right) \delta^{2} T^{2}\left(e^{-\theta T}-e^{-\theta t_{1}}\right)\right. \\
& -2\left(\frac{1-\delta T}{\theta^{2}}\right) \delta\left\{e^{-\theta T}(\theta T+1)-e^{-\theta t_{1}}\left(\theta t_{1}+1\right)\right\} \\
& \left.+\frac{\delta^{2}}{\theta^{3}}\left\{e^{-\theta T}\left(\theta T^{2}+2 \theta T+2\right)-e^{-\theta t_{1}}\left(\theta t_{1}^{2}+2 \theta t_{1}+2\right)\right\}\right] .
\end{aligned}
$$

(e) The cost due to lost sales is given by

$$
\begin{aligned}
L C= & c_{l} \int_{t_{1}}^{T} D(t, p)\left(1-\frac{1}{1+\delta(T-t)}\right) d t \\
\Rightarrow & L C=\frac{c_{l}}{p}\left[\frac{\left(2-\delta T+\delta^{2} T^{2}\right)}{\theta}\left(e^{-\theta T}-e^{-\theta t_{1}}\right)\right. \\
+ & (1+2 \delta T) \frac{\delta}{\theta^{2}} e^{-\theta T}(\theta T+1)+(-1+2 \delta T) \frac{\delta}{\theta^{2}} e^{-\theta t_{1}}\left(\theta t_{1}+1\right) \\
& \left.+\frac{\delta^{2}}{\theta^{3}}\left\{e^{-\theta T}\left(\theta^{2} T^{2}+2 \theta T+2\right)-e^{-\theta t_{1}}\left(\theta^{2} t_{1}^{2}+2 \theta t_{1}+2\right)\right\}\right] .
\end{aligned}
$$


(f) The shortage cost in the entire one cycle is described by

$$
\begin{aligned}
S C= & -c_{s} \int_{t_{1}}^{T} I_{2}(t) d t \\
= & \frac{c_{s}}{p} \int_{t_{1}}^{T}\left[\left(\frac{1-\delta T}{\theta^{2}}\right) \delta^{2} T^{2}\left(e^{-\theta T}-e^{-\theta t_{1}}\right)\right. \\
& \left.-2\left(\frac{1-\delta T}{\theta^{2}}\right) \delta\left\{e^{-\theta T}(\theta T+1)-e^{-\theta t_{1}}\left(\theta t_{1}+1\right)\right\}\right] \\
& \left.+\frac{\delta^{2}}{\theta^{3}}\left\{e^{-\theta T}\left(\theta T^{2}+2 \theta T+2\right)-e^{-\theta t_{1}}\left(\theta t_{1}^{2}+2 \theta t_{1}+2\right)\right\}\right] d t \\
\Rightarrow & S C=\frac{c_{s}}{p}\left[\frac{1}{\theta^{2}}\left\{\left(e^{-\theta t_{1}}-e^{-\theta T}\right)-\theta e^{-\theta t_{1}}\left(T-t_{1}\right)\right\}\right. \\
& +\delta T\left\{\left(T e^{-\theta t_{1}}-\frac{e^{-\theta T}}{\theta}\right)-e^{-\theta t_{1}}\left(t_{1}+\frac{1}{\theta}\right)\right\} \\
& +\frac{\delta}{\theta^{3}}\left\{-e^{-\theta T}(\theta T+2)+e^{-\theta t_{1}}\left(\theta\left(\theta t_{1}+1\right)\left(t_{1}-T\right)\right.\right. \\
& \left.\left.+\left(\theta t_{1}+2\right)\right)\right\}-\frac{\delta T}{\theta}\left\{e^{-\theta T}+e^{-\theta t_{1}}\left(\theta T+\theta t_{1}+1\right)\right\} \\
& +\frac{\delta^{2}}{\theta^{3}}\left\{-\frac{e^{-\theta T}}{\theta}\left(\theta^{2} T^{2}-2\right)+\frac{e^{-\theta t_{1}}}{\theta}\left(\left(-\theta T+\theta t_{1}+1\right)\right.\right. \\
& \left.\left.\left(\theta^{2} t_{1}^{2}+2 \theta t_{1}+2\right)+2\left(\theta t_{1}+2\right)\right)\right\} \\
& \left.+\frac{2 \delta^{2} T}{\theta^{2}}\left\{T\left(e^{-\theta t_{1}}\left(\theta t_{1}+1\right)+e^{-\theta T}\right)-t_{1} e^{-\theta t_{1}}\left(\theta t_{1}+2\right)\right\}\right] .
\end{aligned}
$$

The total cost of the system per cycle is given by

$$
\begin{aligned}
& C F\left(t_{1}, T, p\right) \\
& =\left[\begin{array}{r}
\text { Setup cost } A+\text { Inventory holding/storage cost } H C+ \\
\text { deterioration cost } D C+\text { shortage cost } S C+\text { cost due to lost } \\
\text { sales } L C+\text { purchase cost } P C
\end{array}\right] \\
& \text { or } C F\left(t_{1}, T, p\right)=[A+H C+D C+S C+L C+P C] .
\end{aligned}
$$

Hence, the profit of the system per unit time per cycle is expressed as

$P F\left(t_{1}, T, p\right)=\frac{1}{T}[$ Sales revenue $\mathrm{SR}$

- Total cost of the system $\left.C F\left(t_{1}, T, p\right)\right]$

or $P F\left(t_{1}, T, p\right)=\frac{1}{T}[S R-(A+H C+D C+S C+L C+P C)]$.

\section{Optimality of the profit function}

Case 1: The profit of the system per unit time per cycle $P F\left(t_{1}, T, p\right)$ is function of $t_{1}$ and $p$.

Now in this case the profit of the system per unit time per cycle is expressed as

$$
P F\left(t_{1}, T, p\right)=\frac{1}{T}[S R-(A+H C+D C+S C+L C+P C)] .
$$

The optimal value of $t_{1}$ and $p$ that is $t_{1}^{*}$ and $p^{*}$, obtained by satisfying the following necessary condition

$$
\frac{\partial P F}{\partial t_{1}}=0, \text { and } \quad \frac{\partial P F}{\partial p}=0,
$$

Along with the sufficient condition that is the principal minor of following Hessian matrix $H$ is negative definite.

$$
\mathrm{H}=\left(\begin{array}{cc}
\frac{\partial^{2} P F}{\partial t_{1}^{2}} & \frac{\partial^{2} P F}{\partial t_{1} \partial p} \\
\frac{\partial^{2} P F}{\partial p \partial t_{1}} & \frac{\partial^{2} P F}{\partial p^{2}}
\end{array}\right) .
$$

Case 2: The profit of the system per unit time per cycle $\operatorname{PF}\left(t_{1}, T, p\right)$ is function of only $t_{1}$. Now in this case the profit of the system per unit time per cycle is expressed as

$$
P F\left(t_{1}\right)=\frac{1}{T}[S R-\{A+H C+D C+S C+L C+P C\}] .
$$

The optimal value of $t_{1}$ that is $t_{1}^{*}$ obtained by satisfying the following necessary condition

$\frac{\partial P F\left(t_{1}\right)}{\partial t_{1}}=0, \quad$ along with the following sufficient condition $\frac{\partial^{2} P F}{\partial t_{1}^{2}}<0$.

\section{Results and discussion}

Case 1: The profit of the system per unit time per cycle $P F\left(t_{1}, T, p\right)$ is function of selling price $p$ and time $t_{1}$ when on hand inventory reduces to zero.

\subsection{Numerical analysis}

An inventory system by satisfying both the above necessary and sufficient conditions of maximization, using Mathematica Software, the following parameter in proper unit is derived

$$
\begin{aligned}
& c_{d}=\$ 0.10 / \text { unit }, c_{l}=\$ 0.10 / \text { unit }, c_{h}=\$ 0.10 / \text { unit } / \text { month }, \\
& \mathrm{c}=\$ 2 / \text { unit }, \mathrm{c}_{\mathrm{s}}=\$ 1 / \text { unit }, \theta=0.20 \\
& \alpha=0.08, \beta=2, \delta=0.5, \mathrm{~T}=15 \text { month }
\end{aligned}
$$

Using the above parameter the optimal time $t_{1}^{*}$ when on hand inventory reduces to zero, the optimal selling price $p^{*}$, the optimal order quantity $Q^{*}$ and the optimal profit of the system $P F^{*}$ per cycle respectively is calculated as

The optimal time when on hand inventory reduces to zero $t_{1}^{*}=0.1958$ month

The optimal selling price $p^{*}=\$ 8.45$, 
Optimal order quantity $Q^{*}=14.57$,

Optimal profit of the system per cycle $P F^{*}=\$ 8.10$,

\subsection{Sensitivity analysis}

Sensitivity analysis is carried out by changing the specified parameter c, $\theta, \alpha, \beta$ and $\delta$ by $-50 \%,-25 \%,+25 \%+50 \%$ keeping the remaining parameter at their standard value.

The study from table 1 manifests the following facts.

1. Optimal profit $P F^{*}$ is highly sensitive to the change in the value of parameters $\theta$ and also backlogging parameter $\delta$. It is slightly sensitive to the change in the deterioration parameter $c$. It is moderately sensitive to changes with Weibull parameters $\alpha$ and $\beta$ respectively.

2. Optimal price is highly sensitive in changing the deterioration parameter $c$ and $\theta$ both. Low sensitiveness of $p^{*}$ is observed to the backlogging parameter $\delta$ and moderately sensitiveness to the Weibull parameters $\alpha$ and $\beta$ both.

3. $Q^{*}$ is slightly sensitive in changing the parameter $\delta$ and cbut highly sensitive to the change in the parameter $\theta$ and moderately sensitive to $\alpha$ and $\beta$.

4. $t_{1}^{*}$ is slightly sensitive to the change in parameter $\delta$ and $c$ whereas moderately sensitive to change in $\alpha$ and $\beta$ and highly sensitive to $\theta$.

\subsection{Graphical analysis}

Using the derived above numerical values with the help of Mathematica software, the graphical representation of the effect of selling price $p$ and time $t_{1}$, when on hand inventory reduces to zero, on profit is done in figure 2 as follow:

Case 2: The profit of the system per unit time per cycle $P F\left(t_{1}, T, p\right)$ is function of $t_{1}$ only.

\subsection{Numerical analysis}

An inventory system by satisfying both the above necessary and sufficient conditions of maximization, using Mathematica Software, the following parameter in proper unit is derived

$$
\begin{aligned}
& c_{d}=\$ 1 / \text { unit, } c_{l}=\$ 1 / \text { unit, } c_{h}=\$ 1 / \text { unit/year, } \\
& \mathrm{c}=\$ 2 / \text { unit, } \mathrm{c}_{\mathrm{s}}=\$ 1 / \text { unit, } \theta=5, \\
& \alpha=0.08 \beta=3 ; \delta=0.002 \mathrm{p}=\$ 2, \mathrm{~T}=6 \text { month }
\end{aligned}
$$

Using the above parameter the optimal time $t_{1}^{*}$ when on hand inventory reduces to zero, the optimal order quantity $Q^{*}$ and the optimal profit of the system $P F^{*}$ per cycle respectively is calculated as

The optimal time period when the on hand inventory reduces to zero $t_{1}^{*}=4.16$ month

Optimal order quantity $Q^{*}=148.79$,

Optimal profit of the system per cycle $P F^{*}=\$ 109632$,

\subsection{Sensitivity analysis}

Sensitivity analysis is carried out by changing the specified parameter $c, \theta, \alpha$ and $\beta$ by $-50 \%,-25 \%,+25 \%+50 \%$

\begin{tabular}{|c|c|c|c|c|c|}
\hline Parameters & $\%$ Change & $t_{1}^{*}$ & $p^{*}$ & $Q^{*}$ & $P F^{*}$ \\
\hline \multirow[t]{4}{*}{$c$} & -50 & -160.22 & -3.58 & +16.44 & +12.93 \\
\hline & -25 & -79.20 & -1.80 & +7.84 & +6.22 \\
\hline & +25 & +77.43 & +1.80 & -7.14 & -5.76 \\
\hline & +50 & +153.17 & +3.61 & -13.66 & -11.13 \\
\hline \multirow[t]{4}{*}{$\theta$} & -50 & -3874.46 & +462.25 & +50.69 & +807.01 \\
\hline & -25 & -1670.74 & +25.29 & +151.60 & +225.57 \\
\hline & +25 & -11799.30 & +893.91 & +36786.80 & -12430.60 \\
\hline & +50 & +1801.58 & +1.27 & -83.8372 & -88.94 \\
\hline \multirow[t]{4}{*}{$\alpha$} & -50 & 0.00 & 0.00 & 0.00 & 0.00 \\
\hline & -25 & 0.00 & 0.00 & 0.00 & 0.00 \\
\hline & +25 & 0.00 & 0.00 & 0.00 & 0.00 \\
\hline & +50 & 0.00 & 0.00 & 0.00 & 0.00 \\
\hline \multirow[t]{4}{*}{$\beta$} & -50 & 0.00 & 0.00 & +0.01 & 0.00 \\
\hline & -25 & 0.00 & 0.00 & 0.00 & 0.00 \\
\hline & +25 & 0.00 & 0.00 & 0.00 & 0.00 \\
\hline & +50 & 0.00 & 0.00 & 0.00 & 0.00 \\
\hline \multirow[t]{4}{*}{$\delta$} & -50 & -418.70 & -5.50 & -67.82 & -68.96 \\
\hline & -25 & -136.06 & -1.20 & -39.51 & -39.51 \\
\hline & +25 & +80.08 & +0.35 & +50.58 & +50.58 \\
\hline & +50 & +132.79 & +0.43 & +112.21 & +114.00 \\
\hline
\end{tabular}
keeping the remaining parameter at their standard value.

Table 1. Sensitivity analysis by changing the specified parameter $c, \theta, \alpha, \beta$ and $\delta$ in percentage. 


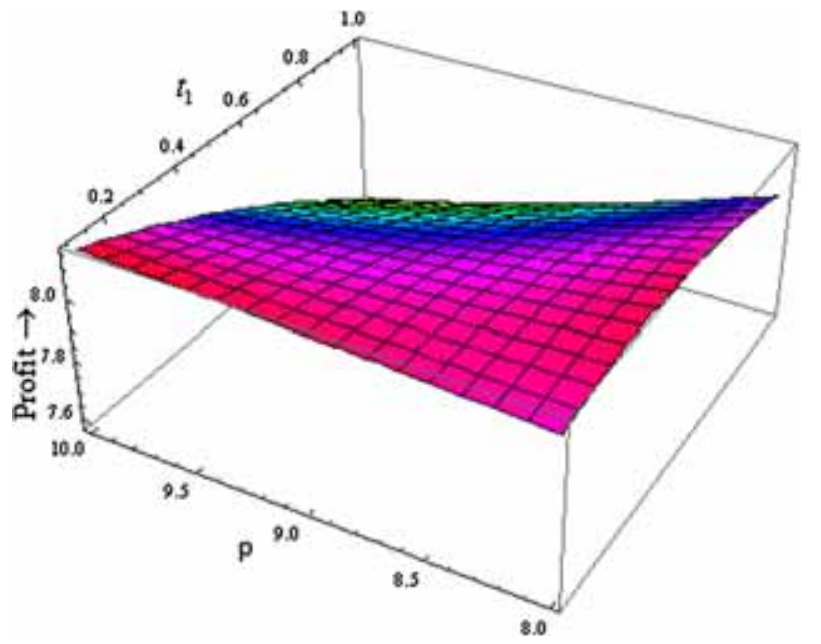

Figure 2. Variation of profit with respect to time $t_{1}$ and price $p$ (case 1).

The study from table 2 manifests the following facts.

1. Optimal profit $P F^{*}$ is highly sensitive with the change in the value of Weibull parameter $\alpha$ and parameter $\theta$ It is moderately sensitive to the change in the deterioration parametercand Weibull parameter $\beta$.

2. $Q^{*}$ is highly sensitive to the change in the Weibull parameter $\alpha$, deterioration parameter cand parameters $\theta$. It is observed that $Q^{*}$ is moderately sensitive to the change in the Weibull parameter $\beta$.

3. $t_{1}^{*}$ is slightly sensitive to the change in Weibull parameter $\beta$ and $\alpha$ whereas highly sensitive to deterioration parameter $c$.

\subsection{Graphical analysis}

Using the derived above numerical values with the help of Mathematica software, the graphical representation of the effect of time $t_{1}$, when on hand inventory reduces to zero, on profit is done in figure 3 as follows:

\section{Conclusions}

An inventory model of the deteriorating item under the effect of selling price and time dependent demand has been investigated. The variation of profit with respect to time and selling price has been exhibited graphically by figure 2 , which shows that at the time $t_{1}^{*}=0.1958$ month and with selling price $\$ 8.45$, profit will be the maximum. The variation of profit with respect to time has been exhibited graphically by the means of figure 3 , which shows that the profit increases with the progress of time and it is maximum at $t_{1}^{*}=4.16$ month. For $t_{1}^{*} \geq 4.16$ monthdecreases rapidly. The model is useful for the commodities for seasonal items like food, vegetable, fashionable materials and electronic products where demand decreases during the end of the season. It is observed that the retailer avail product at a low price when initially received to market, for making the items of the company. So demand is initially high, but as product gets its recognition in the market, its price increases and accordingly the demand decreases due to hike in the price of that product which is in good agreement with these situations of market. Therefore, the choice of the demand function $D(t, p)$ in the present model is decreasing exponentially with time and inversely with price. For the scope of future work, we may extend the proposed model in

Table 2. Sensitivity analysis by changing the specified parameter $c, \theta, \alpha, \beta$ and $\delta$ in percentage.

\begin{tabular}{lcccc}
\hline Parameters & \% Change & $t_{1}^{*}$ & $Q^{*}$ & $P F^{*}$ \\
\hline$c$ & -50 & -175.92 & +523555.00 & -79.0694 \\
& -25 & -163.59 & +36691.00 & -98.39 \\
& +25 & -139.52 & +131.44 & -99.98 \\
$\theta$ & -59.2245 & +99.91 & -100.00 \\
& -50 & +13.43 & -137.109 & -652.31 \\
& -25 & +656.34 & $-658 . .89$ & +101.26 \\
$\alpha$ & +25 & -150.72 & +83.75 & +209.22 \\
& +50 & -5.54 & +337922.00 & -89.93 \\
& -50 & -10.61 & +260.24 & -100.51 \\
$\beta$ & -25 & -60.79 & +40.57 & -100.14 \\
& +25 & -65.87 & -89.91 & -100.01 \\
& +50 & -661.44 & -93.32 & -100.01 \\
& -50 & +19.07 & $9.27 \times 10^{49}$ & $-4.38 \times 10^{47}$ \\
& -25 & -51.39 & +19.80 & +11560.99 \\
& +25 & -52.87 & -80.84 & -100.02 \\
& +50 & -82.76 & -100.02 \\
\hline
\end{tabular}




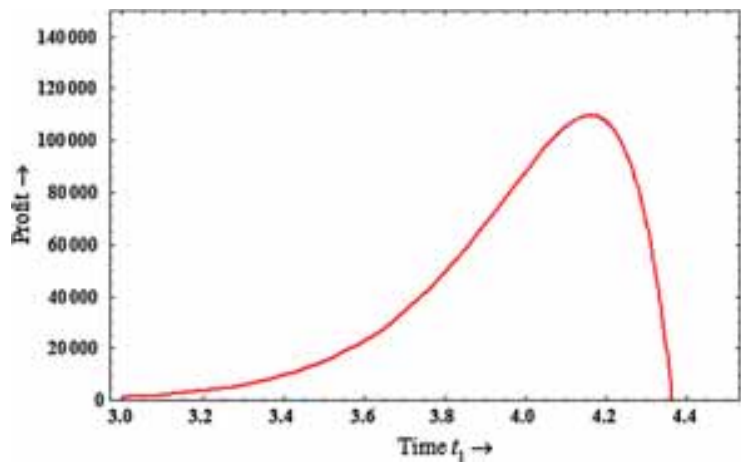

Figure 3. Variation of profit with respect to time $t_{1}$ (case 2).

several ways. We may extend the model by assuming stock dependent demand, price decreasing and time dependent. Besides, this inventory model can be extended by considering as stochastic demand.

\section{Acknowledgement}

One of the authors Mr. Shiv Kumar is grateful to the Indian School of Mines, Dhanbad authorities for financial support in the form of a Research Fellowship and facilitating the best facility. The authors declare that they have no conflict of interest.

\section{References}

[1] Berrotoni J N 1962 Practical applications of Weibull distribution. ASQC Tech. Conf. Trans. 303-323

[2] Papachristos S and Skouri K 2003 An inventory model with deteriorating items, quantity discount, pricing and timedependent partial backlogging. Int. J. Prod. Econ. 83: 247-256

[3] Wee H M 1999 Deteriorating inventory model with quantity discount, pricing and partial backordering. Int. J. Prod. Econ. 59: 511-518

[4] Deng P S 2005 Improved inventory models with ramp type demand and Weibull deterioration. Inform. Manag. Sci.16: 79-86

[5] Wei P, Hua G Yu L, Zhang J, Xie G and Wang S 2009 Determining optimal selling price, order size and the number of price changes with Weibull distribution deterioration. $J$. Comput. 4: 1294-1300

[6] Skouri K, Konstantaras I, Papachristos S and Ganas I 2009 Inventory models with ramp type demand rate, partial backlogging and Weibull deterioration rate. Eur. J. Oper. Res. 192: 79-92
[7] Tripathy P K and Pradhan S 2011 An integrated partial backlogging inventory model having Weibull demand and variable deterioration rate with the effect of trade credit. Int. J. Sci. Eng. Res. 2: 1-5

[8] Valliathal M and Uthayakumar R 2011 A new study of an EOQ model for deteriorating items with shortages under inflation and time discounting. Iranian J. Oper. Res. 2: 48-62

[9] Nandgopal R and Thirumalaisamy V 2012 An inventory model for items with two parameter Weibull distribution deterioration and backlogging. Am. J. Oper. Res. 2: 247-252

[10] Pradhan L M and Tripathy C K 2013 An EOQ model for three parameter Weibull deteriorating item with partial backlogging. Sci. J. Logist. 9: 35-42

[11] Tripathy C K and Pradhan L M 2010 An EOQ model for Weibull deteriorating items with power demand and partial backlogging. Int. J. Contemp. Math. Sci. 5: 1895-1904

[12] Bhaskar B and Rajendra M K 2014 An economic order quantity model for Weibull deteriorating items with stock dependent consumption rate and shortages under inflation. Int. J. Comp. Tech. 1: 196-204

[13] Acharya Milu and Debata Samrutirekha 2007 An inventory model for deteriorating items with time dependent demand under partial backlogging. Int. J. Res. Adent Tech. 2: 1-5

[14] Zhao Q Z and Zhao P X 2007 Improved EOQ model for items with Weibull distribution deterioration. International Conference on Transportation Engineering, pp 2889-2894

[15] Jolai F, Tavakkoli-Moghaddam R, Rabbani $M$ and Sadoughian M R 2006 An economic production lot size model with deteriorating items, stock-dependent demand, inflation, and partial backlogging. Appl. Math. Comput. 181: 380-389

[16] Wu K S 2001 An EOQ inventory model for items with Weibull distribution deterioration, ramp type demand rate and partial backlogging. Prod. Planning Control 12: 787-793

[17] Garg S, Patra K and Pal SK 2014 Particle swarm optimization of a neural network model in a machining process. Sadhana 39(3): 533-48

[18] Hong X, Chunyuan W, Xu L and Diabat A 2016 Multiplevendor, multiple-retailer based vendor-managed inventory. Ann. Oper. Res. 238: 277-297

[19] Chang C T, Teng J T and Goyal S K 2010 Optimal replenishment policies for non-instantaneous deteriorating items with stock-dependent demand. Int. J. Prod. Econ. 123: 62-68

[20] Soto-Silva W E, Nadal-Roig E, González-Araya M C and Pla-Aragones L M 2016 Operational research models applied to the fresh fruit supply chain. Eur. J. Oper. Res. 251: 345-355

[21] Mishra U 2015 A waiting time deterministic inventory model for perishable items in stock and time dependent demand. Int. J. Syst. Assur. Eng. Manag. 1-11. doi:10.1007/s13198015-0404-0 